\title{
КРИТИКА
}

И БИБЛИОГРАФИЯ

Закупень Т.В.

\section{ПОЧЕМУ СИСТЕМА ГОСУДАРСТВЕННОГО УПРАВЛЕНИЯ ФУНКЦИОНИРУЕТ, НО НА ВЫХОДЕ ОБМАНУТЫЕ ОЖИДАНИЯ? РЕЦЕНЗИЯ НА НАУЧНУЮ МОНОГРАФИЮ И.В.ПОНКИНА «ТЕОРИЯ ДЕВИАНТОЛОГИИ ГОСУДАРСТВЕННОГО УПРАВЛЕНИЯ: НЕОПРЕДЕЛЕННОСТИ, РИСКИ, ДЕФЕКТЫ, ДИСФУНКЦИИ И ПРОВАЛЫ В ГОСУДАРСТВЕННОМ УПРАВЛЕНИИ॥}

Аннотация. Объектом исследования в настоящей публикации выступает научная монография профрессора И.В. Понкина «Теория девиантологии государственного управления: Неопределённости, риски, дефекты, дисфункции и провалы в государственном управлении» (Москва, 2016). Автор научной рецензии исследует обозначенную научную монографию с точки зрения релевантности (соответствие ожиданиям по прикладной ценности, применимости) выстроенной в монографии комплексной научной модели. В рецензии содержание анализируемой монографии связывается с недавно озвученными либеральными экономистами проектами трансрормации существующей модели государственного управления в России в модель «проектно-ориентированного государственного управления». Методология исследования определялась целями научного рецензирования и включала методы анализа, индукции и дедукции, метод прогностического моделирования (в части проверки модели на релевантность). Основными выводами проведенного рецензирования монография профессора И.В. Понкина «Теория девиантологии государственного управления: Неопределённости, риски, дефекты, дисфункции и провалы в государственном управлении» (Москва, 2016) являются выводы о высоких актуальности, научной новизне, прикладной ченности этой монографии и представляемой в ней принципиально новой научной теории.

Ключевые слова: теория девиантологии, государственное управление, дисфункция, провал, релевантность, реформа, научная теория, ориентированное управление, систематический сбой, дисбаланс.

Abstract. The research object is the scientific monograph by I.V. Ponkin "The Theory of Public Management Deviance Study: Uncertainties, Risks, Drawbacks, Malfunctions, and Failures of Public Management", Moscow, 2016. The author of the review studies the mentioned scientific monograph from the position of the relevance (compliance with the expectations about applicability) of the complex scientific model proposed in the monograph. The reviewer links the content of the monograph with the projects of transformation of the existing Russian public management model into the model of "project-oriented public management", recently articulated by the liberal economists. The research methodology is conditioned by the purposes of scientific reviewing and includes the methods of analysis, induction and deduction, and the method of prognostic modeling (in terms of the relevance check). The reviewer concludes about the high level of topicality, scientific novelty and practical value of the monograph and the proposed scientific theory.

Key words: imbalance, system failure, oriented management, scientific theory, reform, relevance, failure, malfunction, public management, deviance study theory.

Д октринальная модель понимания, толкования и глубокого теоретического системного описания массива присущих государственному управлению проблем, предложенная профессором И.В.Понкиным в его увидевшей свет научной монографии «Теория девиантологии государственного управления: Неопределённости, риски, дефекты, дисфункции и провалы в государственном управлении» (М., 2016) [1], является фундаментальной и весьма перспективной научной теори- 


\section{Административное и муниципальное право 6 (102) • 2016}

ей, концептуально-доктринальной основой для кардинального реформирования системы государственного управления в Российской Федерации.

Согласно статданным, приведенным 26.04.2016 Интерфаксом, $39 \%$ граждан России считает, что государство по большей части или совершенно не выполняет свои обязанности перед своими гражданами. Убеждены, что если бы вопросы были сформулированы не в обычно свойственной стат-опросам размытой манере, то процент был бы куда выше. Запас доверия В.В.Путину есть, но в целом население, очевидно, не удовлетворено государством, его текущей деятельностью, его (в лице его чиновников) отношением к людям. Справедливости ради скажем, что низкий уровень удовлетворенности населения тем, как государство о нем заботится, как относится к своим гражданам, это беда современного государства вообще, это проблема и США, и Испании, и Франции, и Греции и мн. др., если не вообще всех государств мира. Обманутые ожидания населения - самая большая проблема современного государства.

Недавние идеи Грефа и Кудрина о реформаторском переводе всей системы государственного управления на рельсы «проектно-ориентированного государственного управления», почерпнутые, в том числе, из документов Минэкономразвития России 2014 года, наверно, «всем хороши», кроме одной сущей «мелочи»: совершенно невозможно уяснить ни из публичных выступлений идеологов-лоббистов этого реформаторского подхода (заявляемого как панацея от всех бед), ни из документов Минэкономразвития России, что же это такое - пресловутое «проектно-ориентированное государственное управление». Чем оное выраженно отличается по своей сущности от «процессноориентированного», «риск-ориентированного», «результат-ориентированного», «целе-ориентированного» и проче-ориентированного государственного управления (обусловливавшие реформаторские запалы в предшествовавшие годы). В условиях крайне невнятных, путаных разъяснений и описаний, о чем идет речь в новой (крайне затратной) реформе, таковая очень сильно напоминает очередную дутую кампанию, не имеющую никакого отношения к государевым интересам, но зато призванную достичь одну-единственную цель - набить частные карманы перманентных реформаторов в очередной раз бюджетными деньгами под прикрытием никому не нужных и напрочь лишенных смысла «реформ». Помнится, с какой помпой выводилась десяток лет назад ФМС России из структуры МВД России и как тихо, без лишнего шума была возвращена туда обратно сейчас. Зачем, спрашивается, это надо было затевать в первый раз? Кому нужны такие реформы? Не то же самое ли сейчас с «проектно-ориентированным государственным управлением»?

Но есть и иной подход, помимо очередных «волшебных» реформ, рожденных сознанием очередных американских (про-американских) «гениев». Можно, наконец-то, начать системно и досконально разбираться, где в системе государственного управления систематически происходят сбои, где постоянно имеют место дефекты, дисбалансы и дисфункции государственного управления, кто из начальников и исполнителей может быть обоснованно оценен как токсичный лидер или токсичный исполнитель в государственном управлении (а в силу этого - отправлен куда подальше с занимаемой должности), какие из навязываемых из-за рубежа управленческие технологии подпадают под известный термин «технология дарения “тифозных одеял"».

Пути достижения успеха в таких направлениях в государственном управлении не описаны в учебниках, научных монографиях, статьях или диссертациях. Ничего нет.

Лишь увидевшая свет в этом году научная монография И.В.Понкина подводит под такой обоснованный рациональными соображениями и даже просто здравым смыслом, но упорно не замечаемый нашими руководителями государства подход полноценную научно-теоретическую основу (хотя сам автор и отрицает, что разработал полноценную теорию, говоря лишь о «расширяющемся системном комплексе знаний, находящемся в стадии генезиса и тестирования», о «формирующейся науке», но это - неоправданное скромничание).

В обозреваемой научной монографии совершено значительное приращение научных знаний в области государственного управления, представлено большое число новаторских определений, классификаций, развернутых комплексов дескриптивных признаков. Однако значительные достоинства данной работы не ограничиваются сказанным. Развитие науки не сводится только лишь к приращению научных знаний, не меньшее значение имеет трансформация имеющихся объемов собранных знаний в качественно новые знания, в новые концепты, теории. В работе И.В.Понкина предложена и обоснована новая теория девиантологии государственного управления.

Само это слово («девиантология») в названии предлагаемой теории вызывает определенные нарекания и сомнения. Но, поразмыслив, понимаешь, что при всей дискуссионности этой формулировки выбор замен весьма и весьма скуден и не дает релевантного альтернативного варианта.

Впечатляет ощутимая научная глубина и масштабность ансамблей авторских концептуальнотеоретических построений, колоссальный охват 
разноплановых проблем современного государственного управления.

Ключевой отправной точкой теории И.В.Понкина является тезис о том, что «в общей теории публичного управления и в практике государственного управления... презюмируется, что условия, в которых реализуется такое управление, являются относительно благоприятными и вполне (или хотя бы даже приемлемо) определёнными, отношения в процессе государственного управления - вполне определёнными, подверженными нормальным и линейным зависимостям, подлежащими чёткой схематизации; должностные лица презюмируются как высококвалифицированные и высококомпетентные, безусловно лояльные государству и делающие всё всегда эффективно, безошибочно и надлежащим образом. Это не так практически всегда... Подобных тепличных условий в реальности просто не существует. А вышеозначенный подход основан даже не на идеальной модели, а на примитивизации, на непозволительном упрощении существенных аспектов государственного управления. В действительности, органы государственного управления имеют дело с онтологией, развитием, нелинейными поведением и интерреляциями сложных, открытых, динамических систем, имеют дело со стохастическими процессами, с очень сложными дезорганизациями и дисфункционализациями, развивающимися нелинейно и сложно прогнозируемо, зачастую с нечёткими (или размытыми) множествами объектов управления, обладающих инвариантностью и неоднозначными (гистерезисными) и динамическими характеристиками, в том числе слабоструктурированных и слабоформализованных объектов» (с.12-13).

И.В.Понкин в обозреваемой монографии дает универсальную научную модель, которая вполне применима к разным проблемным сферам. В том числе и к сфере бизнеса. Мы как-то привыкли, что напротив - из сферы бизнеса заимствуются новые подходы и технологии для обогащения арсенала инструментариев государственного управления. В данном же случае, теория из науки государственного управления релевантна и валидна для бизнес-структур, являясь более, чем своевременной.

Почему, несмотря на огромные бюджетные вложения, целый ряд государственных программ по высокотехнологичным направлениям промышленности не реализуются, деньги «растворяются» по многочисленным НИИ и рабочим группам, а результата в конечном итоге вообще никакого нет. Даже если предположить, что деньги не разворовываются, каждый из функционеров, начальников, исполнителей, аналитиков «в поте лица» трудится, что-то предлагает, почему всё же тогда на выходето ничего нет? Всё верно отмечено в обозреваемой монографии - полностью разрушена управленческая система. Или не налажена. Или налажена с существенными дефектами и перекосами.

Почему, задумаемся, деятельность РОСНАНО оказалась провальной (множество проблем с Законом, падение числа финансово поддерживаемых проектов с нескольких десятков до нескольких единиц, отсутствие реального практического выхода, если не считать под таким очередные обещания, прочие реляции)? Почему Президент России систематически уже вынужден поднимать вопрос патологическое неисполняемости в России своих управленческих поручений? Почему, наконец, экономикой и образованием по-прежнему рулят люди, многократно показавшие на практике свою полную неспособность управлять этими сферами, свое фиаско в реформировании этих сфер и в проектах их развития?

В обозреваемой монографии И.В.Понкина мы находим прямые ответы или, по крайней мере, основу для формулирования ответов на эти и многие другие сложные и неоднозначные вопросы.

Книга эта, вне сомнений, станет в своем время классикой, уже сегодня найдя немалое число благодарных и весьма заинтересовавшихся читателей.

\section{Библиография:}

1. Понкин И.В. Теория девиантологии государственного управления. Неопределенности, риски, дефекты, дисфункции и провалы в государственном управлении / ИГСУ РАНХиГС при Президенте РФ / Предисловие д.ю.н., проф. А.Б. Зеленцова. - М.: Буки-Веди, 2016. - 250 с

\section{References (transliterated):}

1. Ponkin I.V. Teoriya deviantologii gosudarstvennogo upravleniya. Neopredelennosti, riski, defekty, disfunktsii i provaly v gosudarstvennom upravlenii / IGSU RANKhiGS pri Prezidente RF / Predislovie d.yu.n., prof. A.B. Zelentsova. - M.: BukiVedi, 2016. $-250 \mathrm{~s}$ 